\title{
Correction to: How is neck dissection performed in Oral and maxillofacial surgery? Results of a representative nationwide survey among university and non-university hospitals in Germany
}

\author{
Andreas Pabst ${ }^{1}$ - Daniel G. E. Thiem ${ }^{2}$ - Elisabeth Goetze ${ }^{3} \cdot$ Alexander K. Bartella $^{4}$ - Michael T. Neuhaus ${ }^{5}$. \\ Jürgen Hoffmann ${ }^{6}$. Alexander-N. Zeller ${ }^{5}$
}

(C) The Author(s) 2021

\section{Correction to: Clinical Oral Investigations. https://doi.org/10.1007/s00784-020-03622-9}

During a routine check, the Open Access coordinator noticed that article https://doi.org/10.1007/s00784-020-03622-9 was published without OA, although the author choose Open Access. Additionally, the article was approved under DEAL on 08/10/2020.

The original article has been corrected.

Open Access This article is licensed under a Creative Commons Attribution 4.0 International License, which permits use, sharing, adaptation, distribution and reproduction in any medium or format, as long as you give appropriate credit to the original author(s) and the source, provide a link to the Creative Commons licence, and indicate if changes were made. The images or other third party material in this article are included in the article's Creative Commons licence, unless indicated otherwise in a credit line to the material. If material is not included in the article's Creative Commons licence and your intended use is not permitted by statutory regulation or exceeds the permitted use, you will need to obtain permission directly from the copyright holder. To view a copy of this licence, visit http://creativecommons.org/licenses/by/4.0/.

Publisher's note Springer Nature remains neutral with regard to jurisdictional claims in published maps and institutional affiliations.

The online version of the original article can be found at https://oi.org/ $10.1007 / \mathrm{s} 00784-020-03622-9$

Andreas Pabst

andipabst@me.com

1 Department of Oral and Maxillofacial Surgery, Federal Armed Forces Hospital, Rübenacherstr. 170, 56072 Koblenz, Germany

2 Department of Oral and Maxillofacial Surgery, University Medical Center Mainz, Augustusplatz 2, 55131 Mainz, Germany

3 Department of Oral and Maxillofacial Surgery, University Hospital Erlangen, Glückstr. 11, 91054 Erlangen, Germany

4 Department of Oral- and Maxillofacial Surgery, University Hospital Leipzig, Liebigstr. 12, 04103 Leipzig, Germany

5 Department of Oral and Maxillofacial Surgery, Hannover Medical School, Carl-Neuberg-Str. 1, 30625 Hannover, Germany

6 Department of Oral and Maxillofacial Surgery, University Hospital Heidelberg, Im Neuenheimer Feld 400, 69120 Heidelberg, Germany 